\title{
COLOUR VISION AND SIDE-EFFECTS DURING TREATMENT WITH METHAZOLAMIDE
}

\author{
INGMAR WIDENGÅRD, AGNETA MANDAHL, PER TÖRNQUIST and PER J. WISTRAND \\ Uppsala, Sweden
}

\begin{abstract}
SUMMARY
The retina contains $\mathrm{Na}^{+} \mathrm{K}^{+}$-ATPase and carbonic anhydrase (CA), enzymes that regulate ion fluxes across cell membranes of photoreceptors. Since inhibition of retinal $\mathrm{Na}^{+} \mathrm{K}^{+}$-ATPase by digitalis impairs colour vision, we wanted to find out whether this also occurs after inhibition of CA. In a double-masked crossover study with placebo, 14 male volunteers were given $50 \mathrm{mg}$ q.i.d. of the $\mathrm{CA}$ inhibitor methazolamide for 2 weeks. A disturbance of colour discrimination was observed in 8 of the 14 subjects, in the classification phase of Lanthony New Color Test. The presence of the disturbance was not significantly correlated to the degree of acidosis or to other side-effects. Its mechanism could be interpreted as a specific effect of $\mathrm{CA}$ inhibition in the retina (or the visual cortex) calculated to more than $99.9 \%$.
\end{abstract}

The retina contains $\mathrm{Na}^{+} \mathrm{K}^{+}$-ATPase ${ }^{1}$ and carbonic anhydrase $^{2,3}$ (CA; carbonate hydrolyase EC 4.2.1.1), enzymes that directly or indirectly regulate ion fluxes across cell membranes of the photoreceptors. ${ }^{4,5}$ Inhibition of $\mathrm{Na}^{+} \mathrm{K}^{+}$-ATPase by digitalis has been found to impair blue-yellow (in mild digitalis intoxication) and red-green (in severe intoxication) colour vision. ${ }^{6,7}$ This effect can be conveniently evaluated by the Farnsworth-Munsell 100-Hue Test. ${ }^{8}$ It was therefore of interest to find out whether colour vision is affected by inhibition of CA also, and if so, whether this is related to other side-effects known to occur ${ }^{9,10}$ in patients given CA inhibitors.

\section{MATERIALS AND METHODS}

The study was approved by the Ethics Committee of the Medical Faculty of Uppsala University.

Fourteen healthy men, aged 21-39 years, were invited to participate in the study, which was designed as a cross-over study with placebo. All

From: Department of Ophthalmology, University of Uppsala, Uppsala, Sweden.

Correspondence to: Ingmar Widengård, MD, Department of Ophthalmology, University Hospital, S-751 85 Uppsala, Sweden. subjects had normal visual acuity, normal colour vision as assessed with pseudoisochromatic tables and a Nagel Anomaloscope, normal ocular fundi, and no history of eye diseases. The CA inhibitor chosen was methazolamide USP (Neptazane, Lederle division, Nordiska Cyanamid AB, Sundbyberg, Sweden). Methazolamide is a relatively lipidsoluble inhibitor that is known to cross the blood-brain and blood-aqueous barriers easily. ${ }^{11}$ Placebo tablets made to match the $50 \mathrm{mg}$ methazolamide tablets were a generous gift of American Cyanamid Co. (Pearl River, NY, USA). Methazolamide and placebo tablets were dispensed in identical, coded bottles, randomly allocated to the subjects and labelled with directions for taking one tablet every 6 hours, i.e. the highest dose recommended by the USP. The bottles were fitted with a cap containing a microprocessor (Medication Event Monitoring System, MEMS, Aprex Col., Fremont, CA, USA), which recorded every opening and closing as a presumptive dose. The data were sent on diskette to the Aprex Corporation for analysis. Information was provided as listings of the time and date of openings and closing, the duration of opening, and the time between the individual doses. Each subject was first given active drug or placebo for 2 weeks. After a 'wash-out' period without medication for at least 2 weeks, he then switched to either placebo or drug for another 2 week period.

Prior to medication colour vision tests were performed and the intraocular pressures (IOP) were measured in duplicate on each eye with the Goldmann applanation tonometer. Blood samples were drawn into heparinised tubes and analysed for $\mathrm{pH}$ and total carbon dioxide $\left(\mathrm{CO}_{2}\right)$, using standard hospital techniques. After centrifugation of the blood, the plasma was separated, frozen and shipped to the Product Research and Development Laboratory, Gosport, UK, for assay of its concentration of methazolamide. Samples were analysed in duplicate 
Table I. Levels (mean $\pm \mathrm{SD}$ ) of methazolamide and $\mathrm{CO}_{2}$ in plasma and of intraocular pressures (IOP) before and after 14 days of treatment with either methazolamide $50 \mathrm{mg}$ q.i.d. or placebo, in 14 healthy male volunteers

\begin{tabular}{|c|c|c|c|c|c|}
\hline \multirow[b]{2}{*}{ Parameter } & \multirow[b]{2}{*}{$n$} & \multicolumn{2}{|c|}{ Placebo } & \multicolumn{2}{|c|}{ Drug } \\
\hline & & Before & After & Before & Aftera \\
\hline $\begin{array}{l}\text { Methazolamide }(\mu \mathrm{M}) \\
\mathrm{CO}_{2}(\mathrm{mM}) \\
\mathrm{IOP}(\mathrm{mmHg})\end{array}$ & $\begin{array}{l}14 \\
14 \\
13\end{array}$ & $\begin{array}{c}0 \\
26.1 \pm 1.0 \\
14.9 \pm 2.2\end{array}$ & $\begin{array}{c}0 \\
25.6 \pm 2.3 \\
13.7 \pm 2.2\end{array}$ & $\begin{array}{c}0 \\
25.5 \pm 1.2 \\
15.0 \pm 2.1\end{array}$ & $\begin{array}{l}35.9 \pm 5.5 \\
21.8 \pm 1.5 \\
14.5 \pm 2.1\end{array}$ \\
\hline
\end{tabular}

${ }^{\mathrm{a}}$ Time interval between ingestion of the last tablet and measurements was 130 minutes (range $=60-236$ minutes) on average. Compliance was $95 \%$ of prescribed doses.

using a reverse phase high-performance liquid chromatography system with internal standard.

At the end of the 2 week medication period, and between 1 and 4 hours (mean 2 hours) after the last tablet had been taken, the same tests were repeated. In addition the occurrence of several side-effects ${ }^{9}$ were recorded, evaluated as none (0), mild (1), moderate (2) and severe (3), respectively.

Colour vision was tested with two sorting tests using caps with pigment colours: the Farnsworth-Munsell 100-Hue Test $(\mathrm{F}-100)^{12}$ and the Lanthony New Color Test (NCT) ${ }^{13}$ The F-100 is widely used as a clinical test for both congenital and acquired colour vision abnormalities. It measures the ability to recognise and accurately classify small differences in hue. It was used here in its original version with 85 caps.

The NCT is designed specifically for use in acquired colour vision defects. It is performed in two phases. The first phase (separation) allows the determination of neutral zones according to the coloured hues confused with the greys at four saturation levels. The second phase (classification)

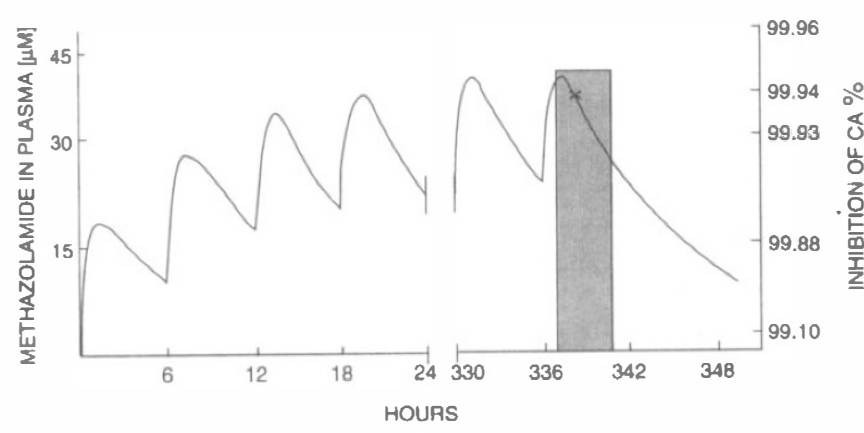

Fig. 1. Mean steady-state plasma concentration in 14 subjects taking $50 \mathrm{mg}(212 \mu \mathrm{mol})$ methazolamide tablets every 6 hours, giving a mean single dose of $2.6 \pm 0.1$ (SEM) umol/kg. The concentration in plasma at $2(1-4) h$ after ingestion of the last tablet was $35.9 \pm 1.5$ (SEM) $\mu M$. The shaded area is the time of measurements. The ordinate to the right shows the degree of carbonic anhydrase (CA) inhibition at various concentrations. In the simulation the following pharmacokinetic parameters were used: volume of drug distribution, 10 litres; $\mathrm{t}_{1 / 2}$ for elimination of unbound (45\%) drug, $6 \mathrm{~h}$; rate of invasion (gut to plasma) $1.3 \mathrm{~h}^{-1}$. The mean plasma concentration is so high compared with the $\mathrm{K}_{i}\left(\sim 10^{-8} \mathrm{M}\right)$ of the drug against the red cell enzymes, that the half-life of elimination is not blocked by the binding

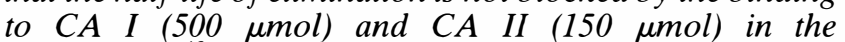
erythrocytes. 40 allows the determination of chromatic discrimination by the arrangement of the coloured hues. The hues can be presented in four different levels of saturation, two of them lower and two higher than the one in the F-100.

The two tests were administered binocularly and under standard illumination. The individual was allowed free time to arrange the caps in an order with which he was satisfied. A session was provided before the first base-line test to reduce learning effects. On each occasion the volunteer performed two F-100s and one NCT.

Evaluation of the subject's performance in the F100 was done as described previously. ${ }^{14-16}$ We also analysed the inter-test variance at each occasion. In the classification phase of NCT the defects were rated as: $0=$ no mistake, $1=$ single mistake between neighbouring caps, $2=$ several mistakes.

\section{Statistical Analysis}

For each individual, the difference between the effects of placebo and drug was calculated with respect to every recorded parameter. Using these differences, the correlation between the various parameters was analysed by the $t$-test and by a non-parametric statistical test, the Wilcoxon signedrank test. ${ }^{17}$ A significant difference was defined as $p<0.01$.

\section{Compliance}

\section{RESULTS}

The definition of non-compliance was omission of a scheduled dose. The 14 subjects, who were prescribed 784 doses of either methazolamide or placebo in 14 days, showed a mean compliance of $95 \pm 7 \%$ and $87 \pm 11 \%$ (SD), respectively. During the medication period the doses were correctly taken on $77 \%$ of the days, for both drug and placebo, and on $99 \%$ during the last 3 days of active drug. If adherence to. scheduled times was defined as \pm 3 hours, the number of doses of active drug taken on schedule was $35 \pm 9 \%$ and of placebo $26 \pm 6 \%$.

\section{Methazolamide Concentrations in Plasma}

In the subjects taking active drug, the plasma concentrations of methazolamide (Table I) ranged between 6.2 and $10.5 \mu \mathrm{g} / \mathrm{ml}$ at the time when IOP and total $\mathrm{CO}_{2}$ were measured, and side-effects 
Table II. Side-effects in 14 healthy volunteers at 2 weeks after treatment with methazolamide, $50 \mathrm{mg}$ tablets q.i.d.

\begin{tabular}{|c|c|c|c|c|c|c|c|c|c|c|c|c|}
\hline \multirow[b]{2}{*}{ Side-effects ${ }^{\mathrm{a}}$} & \multicolumn{12}{|c|}{ Subject } \\
\hline & 1 & 2 & 3 & 4 & 5 & 6 & 7 & 8 & 9 & & 1112 & 131 \\
\hline Defects in colour & 0 & 1 & 0 & 0 & 1 & 2 & 2 & 0 & 1 & 12 & 22 & 0 \\
\hline Paraesthesias & 0 & & 1 & 1 & 1 & 1 & 1 & 1 & 1 & 1 & 02 & 0 \\
\hline & 0 & 0 & 0 & 0 & 1 & 1 & 0 & & 0 & & $0 \quad 0$ & 0 \\
\hline ea & 1 & 0 & 0 & 0 & 0 & 0 & 0 & 0 & 0 & 0 & $\begin{array}{ll}0 & 1\end{array}$ & $0 \quad 0$ \\
\hline & 2 & 0 & 0 & 1 & 0 & 0 & 0 & 0 & 0 & 0 & $0 \quad 0$ & 0 \\
\hline & 0 & 0 & 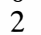 & 0 & 0 & U & & 0 & 2 & 0 & $0 \quad 0$ & 0 \\
\hline $\mathrm{d}$ taste & 2 & 0 & 0 & 0 & 2 & 2 & 2 & & 0 & 0 & $0 \quad 0$ & 02 \\
\hline & 1 & 0 & 0 & 0 & 0 & 0 & 0 & 0 & 0 & 0 & $0 \quad 0$ & \\
\hline $\mathrm{h}$ & & 1 & 1 & 0 & 0 & & & & & & 22 & \\
\hline & 2 & 0 & 0 & 2 & 1 & 0 & 0 & 2 & 0 & 1 & $0 \quad 0$ & 01 \\
\hline $\mathrm{Al}$ & 1 & 0 & 0 & 1 & 1 & 0 & 1 & 0 & 1 & 0 & $\begin{array}{ll}0 & 0\end{array}$ & \\
\hline Leg cramps & 1 & 0 & 0 & 0 & 0 & 0 & 0 & & & & $\begin{array}{ll}0 & 1\end{array}$ & \\
\hline \multicolumn{13}{|c|}{$\begin{array}{l}\text { a Defects in colour vision were rated as: } 0=\text { no mistake, } 1=\text { single } \\
\text { mistake between neighbouring caps, } 2=\text { several mistakes. Other } \\
\text { side-effects were rated as: } 0=\text { no reaction, } 1=\text { mild reaction, } 2= \\
\text { moderate. } \\
{ }^{b} \text { Subject } 1 \text { exhibited a defect (1) in colour vision before taking } \\
\text { methazolamide but not after, and subject } 14 \text { had a similar defect } \\
\text { (1) after placebo. Subject } 7 \text { had a defect (1) before both } \\
\text { methazolamide and placebo. After placebo he showed no defect, } \\
\text { but after methazolamide he made several mistakes. }\end{array}$} \\
\hline
\end{tabular}

recorded. The drug could not be detected in plasma $(<0.5 \mathrm{ng} / \mathrm{ml})$ after the wash-out period, indicating that it had been eliminated from the plasma in those subjects taking placebo after this period. There was no significant difference between the values after the two methazolamide periods. The plasma values, and the times for taking the drug, were used to simulate the steady-state concentrations of methazolamide during the 2 week period. This simulation was done with a pharmacokinetic programmed (I think ${ }^{\mathrm{TH}}$. Software from High Performance Systems Inc., Hanover, NH, USA) executed on a computer. The pharmacokinetic parameters used in the simulation are given in the legend to Fig. 1. The curve shows that the colour tests were performed while plasma levels were still high.

\section{Plasma Carbon Dioxide Levels}

Methazolamide significantly lowered the mean plasma $\mathrm{CO}_{2}$ in the 14 subjects $(p<0.001)$, whereas placebo had no such effect (Table I). The wash-out period allowed the plasma $\mathrm{CO}_{2}$ to return to normal.

\section{Intraocular Pressure}

Methazolamide had no significant effect on IOP (Table I). The IOP in these healthy eyes was $15 \pm 2$ (SD) $\mathrm{mmHg}$, giving a mean outflow pressure of 5 $\mathrm{mmHg}$, assuming the episcleral venous pressure to be 10 $\mathrm{mmHg}$.

\section{Side-effects}

Methazolamide caused significantly more side-effects than placebo $(p<0.001$; Table II). The only sideeffects reported after placebo were mild polyuria (subject 1) and mild constipation (subject 13).

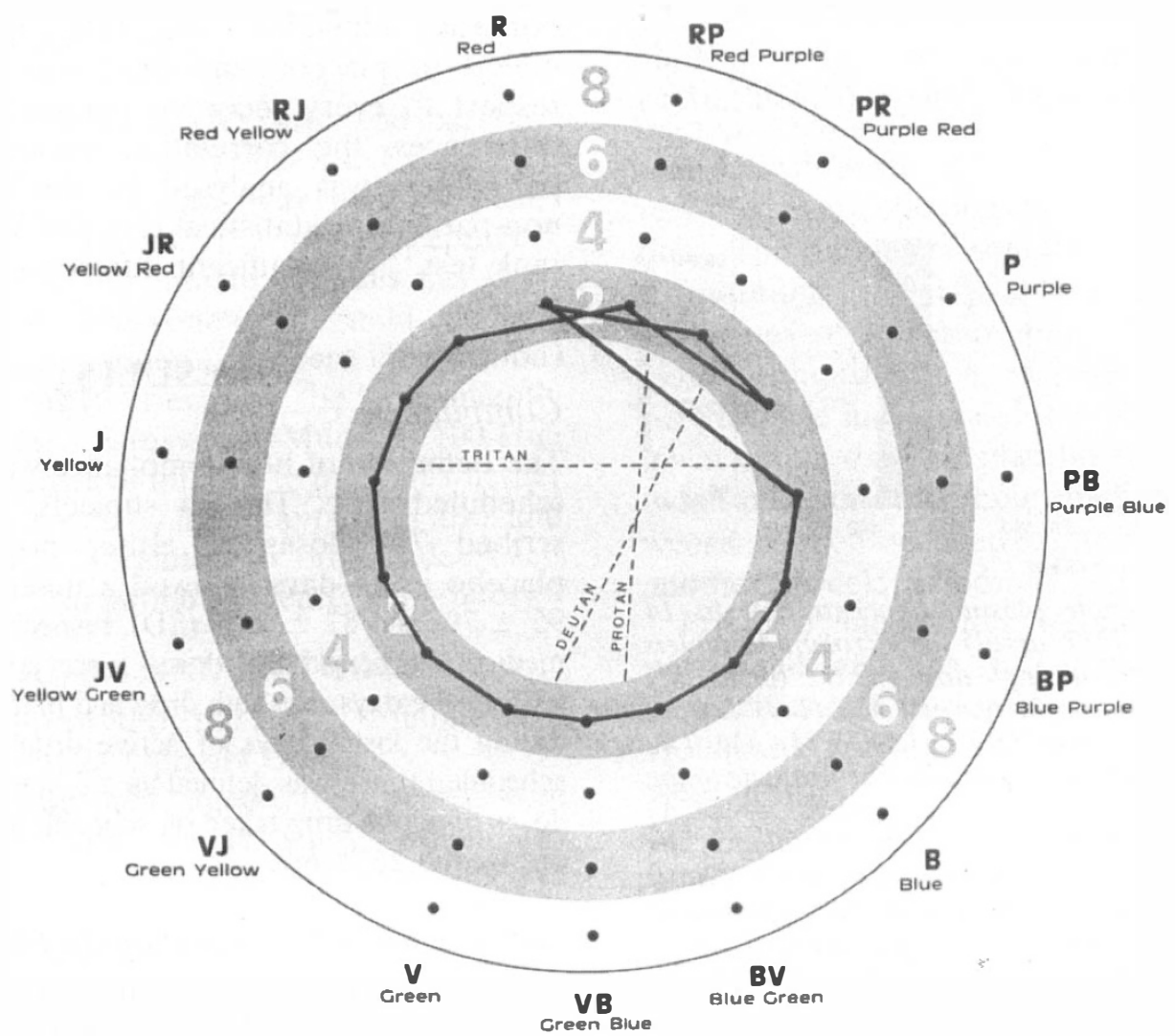

Fig. 2. Performance of subject 7 in the classification phase of the Lanthony New Color Test. The subject has misplaced the caps in the tritan and protan directions. 
Methazolamide induced a mean of 3.7 side-effects in each individual, but with a wide range. For example subject 13 reported no reactions, whereas subject 1 reported eight of the listed reactions. Paraesthesias, flat taste of carbonated beverages, shortness of breath and fatigue were the most frequent sideeffects (42-68\%). They were not significantly correlated to levels of methazolamide or plasma $\mathrm{CO}_{2}$. No symptoms of kidney stones, blood dyscrasias or other rare side-effects that have been observed after administration of carbonic anhydrase inhibitors ${ }^{18}$ were noted.

\section{Effect on Colour Vision}

The performance of the subjects in the F-100 and in the separation phase of the NCT was not altered significantly by methazolamide or placebo. Neither was the inter-test variation between the two F-100 at the same visit. However, in the classification phase of NCT methazolamide significantly $(p<0.01)$ increased the number and degree of mistakes (Table II) when compared with placebo. All but one subject (no. 7) made the errors in a direction between tritan and protan; one was clearly protan. Most errors were made with the caps around red and purple. Fig. 2 shows the mistakes in placing the caps done by subject 7. The defects in colour vision were not significantly correlated to the levels of methazolamide and total $\mathrm{CO}_{2}$ in plasma, nor to the other sideeffects.

\section{DISCUSSION}

The compliance was very high considering that tablets were to be taken four times a day and that rather disturbing side-effects were experienced during the treatment with methazolamide. ${ }^{19,20}$ The high compliance is reflected in the rather narrow range of drug concentrations in plasma. These concentrations are in agreement with those reported from other long-term studies ${ }^{21}$ using similar dosage regimens. They are known to induce a metabolic acidosis of 4-5 $\mathrm{mM}$ reduction of plasma $\mathrm{CO}_{2},{ }^{10,11}$ and a reduction of plasma $\mathrm{K}^{+}$and $\mathrm{Na}^{+22}$ through inhibition of CA in the kidney. ${ }^{11}$ Such effects were also observed in our subjects (Table I).

Acidosis alone reduces $\mathrm{IOP}^{23}$ an effect that is additive to the direct effect of inhibition of CA in the ciliary epithelium. It was calculated that the inhibition of CA in this epithelium (and in the retina) was $>99.9 \%$ in our subjects (Fig. 1), since their mean steady-state plasma level of freely diffusible methazolamide was $16 \mu \mathrm{M}$, and the $K_{\mathrm{i}}$ for methazolamide against $\mathrm{CA} \mathrm{II}^{11}$ and the membrane-associated $\mathrm{CA}^{24}$ is $0.01 \mu \mathrm{M}$ (Fig. 1). A lowering effect on IOP can be seen already at plasma concentrations (total drug) of $2 \mu \mathrm{M}^{11}$ corresponding to an enzyme inhibition of $99.1 \%$. Methazolamide given in daily doses of 100 mg or more ${ }^{22}$ has been found to lower IOP in most patients with ocular hypertension ${ }^{11}$ or glaucoma $^{25}$ with pressures above $20 \mathrm{mmHg}$. However, $9-17 \%$ of such patients have been reported to be nonresponders. ${ }^{21,26}$ The acidosis and high levels of methazolamide in plasma would have been expected to reduce the IOP in our subjects. The lack of a significant effect is probably due to the difficulty in measuring a reduction of the low outflow pressures of $5 \mathrm{mmHg}$, as seen in the eyes of our subjects. A lack of effect of methazolamide in normal eyes has previously been reported. $^{27}$

The number of side-effects reported by the individual subjects was very similar to that reported $^{9,10}$ in glaucoma patients after 1 week of treatment with methazolamide, using the same dosage regimen. Most of our subjects experienced paraesthesias, an altered taste of carbonated beverages, fatigue, and shortness of breath. The last is said to be the most disturbing side-effect and is probably due to the mixed respiratory and metabolic acidosis caused by the inhibition of CA in the red cells and kidney, respectively. ${ }^{11}$ However, there was no significant correlation between the plasma levels of $\mathrm{CO}_{2}$ and the side-effects. A positive correlation has previously been found ${ }^{10}$ between the syndrome of malaise and excessive systemic acidosis, i.e. values of $\mathrm{CO}_{2}$ in plasma lower than $21 \mathrm{mM}$. However, inhibition of $\mathrm{CA}$ in the brain, i.e. in the glial cells, may also play a role, since the more lipid-soluble inhibitors, such as ethoxzolamide, that are known to cross the blood-brain barrier easily, produce a higher incidence of this type of effect than less lipid-soluble ones. ${ }^{28}$ The sensitivity towards shortness of breath in our subjects, many of them athletes, is probably explained by the daily physical demand on these young men, making them aware of any type of incapacitation. In this context it should be mentioned that reducing the dose of methazolamide to $25 \mathrm{mg}$ three times daily results in very few side-effects with no malaise, paraesthesias or flat taste. ${ }^{11}$

The rather high incidence $(57 \%)$ of defective colour vision after intake of methazolamide is a new finding. This defect was observed only in the classification phase of the NCT, where the lowest saturation series was used. The saturation of this series is much lower than that of the F-100 and there is also a slight difference in lightness. It is possible that the minor defects diagnosed in our subjects are detectable only in healthy eyes of young adults. The possibility of a non-specific effect can naturally not be ruled out, but is made less probable by two observations. We found no positive correlation between colour vision disturbance and any of the other effects of CA inhibition; on the contrary a weak negative correlation between the presence of NCT mistakes and the notion of fatigue can be 
traced. If lack of concentration be the cause of the mistakes, a greater variation between the two F-100s performed at the same visit would also be expected, and this was clearly not the case.

We propose that the defect is due to inhibition of CA activity in the retina, and perhaps of the activity in the cones. The mammalian retina has the same high specific CA activity as the kidney, ${ }^{29}$ an activity shown to originate from a high-activity (with respect to hydration of $\mathrm{CO}_{2}$ ) cytoplasmic isoform CA II, and a membrane-associated isoform. ${ }^{28}$

In the human retina, CA II has been localised by immunohistochemical and histochemical methods in Müller cells, ${ }^{2,30,31}$ in certain cones, ${ }^{2,30}$ probably the red-and green-sensitive ones, ${ }^{3}$ and in retinal pigment epithelium (RPE). ${ }^{2}$ Membrane-associated activity has been similarly localised in Müller cells, in CA II-containing cones, ${ }^{2}$ in apical and basolateral membranes of RPE, ${ }^{2}$ and in the choroidal capillary endothelium. ${ }^{2,32}$

The function of cytoplasmic CA II in the retina is probably to modulate the intracellular $\mathrm{pH}$ and to secure a rapid supply of $\mathrm{CO}_{2}, \mathrm{HCO}_{3}{ }^{-}$and $\mathrm{H}^{+}$, for the transcellular ionic transport systems. Acidification of the retina depresses the light sensitivity of the photoreceptors. ${ }^{33}$ However, the intracellular $\mathrm{pH}$ of the photoreceptors is also dependent on the rate of $\mathrm{H}^{+}$leakage out of, and of $\mathrm{HCO}_{3}{ }^{-}$transport into, the receptors, and thus on the concentrations of these ions in the retinal extracellular space. The boundary of this space in the distal retina is formed by the Müller cells, the photoreceptors of the RPE. The rods of the cat retina have been shown to acidify the extracellular space in the dark. ${ }^{34}$ Lactic acid is produced in the outer nuclear layer and generates $\mathrm{CO}_{2}$ by titration of bicarbonate. ${ }^{34}$ The abovementioned cells all have membrane-associated CA activity, the role of which is probably to regulate and modulate the extracellular $\mathrm{pH}$ gradients created by the metabolic activity of the retina. Another function would be to maintain a steady concentration of bicarbonate outside the photoreceptor, an ion shown to be critical for intracellular $\mathrm{pH}^{5,35}$ and thus, for phototransduction. Indeed, selective inhibition of the membrane-associated CA activity in the brain glial cells has been shown to increase the shift of $\mathrm{pH}$ in the extracellular space associated with neuronal activity. ${ }^{36}$

Intravenous administration of the $\mathrm{CA}$ inhibitor acetazolamide has been found to lower the $\mathrm{pH}$ in the outer $^{37}$ and inner ${ }^{38}$ retina of the cat and pig, respectively, and to decrease the standing potential of the human eye. ${ }^{39}$ The latter effect was thought to emanate from RPE. The defect in colour vision seen in our subjects is probably due to dysfunction of the green- and red-sensitive cones. In the light of the above discussion, it would seem clear that the effect could be due to inhibition of CA in the cones proper, or in the cells, including the capillary endothelial cells, which participate in the regulation of $\mathrm{pH}$ and bicarbonate ions in the retinal extracellular space.

To differentiate the effect on the various cells in the neuroretina it would be of interest to find out whether methazolamide can cause a cone dysfunction detectable by the electroretinogram. However, even if this proves to be the case, it does not rule out the existence of additional colour vision disturbance through inhibition of carbonic anhydrase in the glial cells of the visual cortex.

Supported by the Swedish Medical Research Council (grant no. 2874 to P.J.W.), by the Crown Princess Margareta Employment Board for the Visually Handicapped and by Zetterlings Foundation. Proprietary interest category: $\mathrm{N}$. The authors wish to thank Mr Börje Nordh for performing the colour vision tests and Mrs S. A. Yeats of the Product Research \& Developmental Laboratory of Cyanamid UK, Gosport, UK, for the assays of methazolamide in the plasma samples.

Key words: Carbonate dehydratase, Colour perception, Cones, Glaucoma, Retina.

\section{REFERENCES}

1. Bonting SL, Simon KA, Hawkins NM. Studies on sodium-potassium-activated adenosine triphosphatase. I. Quantitative distribution in several tissues of cat. Arch Biochem Biophys 1961;95:416-23.

2. Wistrand PJ, Schenholm M, Lönnerholm G. Carbonic anhydrase isoenzymes CA I and CA II in the human eye. Invest Ophthalmol Vis Sci 1986;27:419-28.

3. Nork TM, McCormick SA, Chao G-M, Odom JV. Distribution of carbonic anhydrase among human photoreceptors. Invest Ophthalmol Vis Sci 1990; 31:1451-8.

4. Oakley B II, Fleming DGF, Brown KT. Effects of the the rod receptor potential upon retinal extracellular potassium concentrations. J Gen Physiol 1979;74: 713-37.

5. Donner K, Hemilä S, Kalamakarov G, Koskelainen A, Schevchenko T. Rod phototransduction modulated by bicarbonate in the frog retina: roles of carbonic anhydrase and bicarbonate exchange. J Physiol (Lond) 1990;426:297-316.

6. Weleber RG, Shults T. Digoxin retinal toxicity: clinical and electrophysiologic evaluation of a cone dysfunction syndrome. Arch Ophthalmol 1981;99:1568-72.

7. Woodcock BG, Rietbrock N. Colour vision in clinical pharmacology. TIPS 1983;4:447-8.

8. Duncker G, Horst H-A, Kolenda K-D, Schenk F. Farbsinnstörungen bei subtoxischen und toxischen Digoxin- und Digitoxinserumkonzentrationen. Klin Monatsbl Augenheilkd 1988;193:622-6.

9. Lichter PR, Newman LP, Wheeler NC, Beall OV. Patient tolerance to carbonic anhydrase inhibitors. Am J Ophthalmol 1978;85:495-502.

10. Epstein DL, Grant WM. Carbonic anhydrase inhibitor side effects: serum chemical analysis. Arch Ophthalmol 1977;95:1378-82.

11. Maren TH, Haywood JR, Chapman SK, Zimmerman TJ. The pharmacology of methazolamide in relation to the treatment of glaucoma. Invest Ophthalmol Vis Sci 1977;16:730-42. 
12. Farnsworth DJ. The Farnsworth-Munsell 100 Hue and dichotomous tests for color vision. J Opt Soc Am 1943;33:568-78.

13. Lanthony P. The new color test. Doc Ophthalmol 1978;46:191-9.

14. Helve J. A comparative study of several diagnostic tests of colour vision used for measuring types and degrees of congenital red-green defects. Acta Ophthalmol (Copenh) Suppl 1972;115:1-64.

15. Vingrys AJ, King-Smith E. A quantitative scoring technique for panel tests of color vision. Invest Ophthíalmol Vis Sci 1988;22:50-63.

16. Smith VC, Pokorny J, Pass AE. Color-axis determination on the Farnsworth-Munsell 100-hue test. Am J Ophthalmol 1985;100:176-82.

17. Armitage P, Berry G. Statistical methods in medical research. Oxford: Blackwell Scientific, 1987.

18. Werblin TP, Pollack JP, Liss RA. Aplastic anemia and agranulocytosis in patients using methazolamide for glaucoma. JAMA 1979;241:2817-8.

19. Alward PD, Wilensky JH. Determination of acetazolamide compliance in patients with glaucoma. Arch Ophthalmol 1981;99:1973-6.

20. Cramer JA, Mattson RA, Prevey ML, Scheyer RD, Guellette VL. How often is medication taken as prescribed? A novel assessment technique. JAMA 1989;261:3273-7.

21. Dahlen K, Epstein DL, Grant WM, Hutchinson BT, Prien Jr EL, Krall JM. A repeated dose-response study of methazolamide in glaucoma. Arch Ophthalmol 1978;96:2214-8.

22. Merkle W. Untersuchungen über die Wirkung von Methazolamid auf den intraokularen Druck. Klin Monatsbl Augenheilkd 1980;176:181-5.

23. Wistrand P, Maren TH. The effects of carbonic anhydrase inhibition on intraocular pressure of rabbits with different blood $\mathrm{CO}_{2}$ equilibria. Am J Ophthalmol 1961;50:291-6.

24. Maren TH, Wynn GC, Wistrand PJ. Chemical properties of carbonic anhydrase IV, the membrane-bound enzyme. Mol Pharmacol 1993;44:901-5.

25. Lichter PR, Musch DC, Medzihradsky F, Standardi CL. Intraocular pressure effects of carbonic anhydrase inhibitors in primary open-angle glaucoma. Am J Ophthalmol 1989;107:11-7.

26. Becker B. Use of methazolamide (Neptazane) in the therapy of glaucoma: comparison with acetazolamide (Diamox). Am J Ophthalmol 1960;49:1307-11.
27. Kandori F, Kurose Y, Kurimoto A. Clinical effects of Neptazane. Am J Ophthalmol 1960;40:1395-400.

28. Wistrand PJ. The use of carbonic anhydrase inhibitors in ophthalmology and clinical medicine. Ann NY Acad Sci 1984;429:609-19.

29. Trachtenberg MC, Packey DJ. Retinal carbonic anhydrase: a comparative study. Curr Eye Res 1984; 3:599-604.

30. Musser GL, Rosen S. Carbonic anhydrase activity in primate photoreceptors. Exp Eye Res 1973;15:467-73.

31. Kumpulainen T. Carbonic anhydrase isoenzyme $C$ in the human retina: an immunohistochemical study. Acta Ophthalmol (Copenh) 1980;58:397-405.

32. Hageman GS, Zhu XL, Waheed A, Sly WS. Localization of carbonic anhydrase IV in a specific capillary bed of the human eye. Proc Natl Acad Sci USA 1991; $8: 2716-20$.

33. Meyerholen EP, Wilson MJ, Ostroy SE. The effects of HEPES, bicarbonate and calcium on the cGMP content of vertebrate rod photoreceptors and the isolated electrophysiological effects of cGMP and calcium. Vision Res 1986;26:521-33.

34. Yamamoto F, Borgula GA, Steinberg RH. Effects of light and darkness on $\mathrm{pH}$ outside photoreceptors in the cat retina. Exp Eye Res 1992;54:685-97.

35. Winkler BS, Simmon V, Benner J. Importance of bicarbonate in retinal function. Invest Ophthalmol Vis Sci 1977;16:766-8.

36. Chen JCT, Chesler M. pH transients evoked by excitatory synaptic transmission are increased by inhibition of extracellular carbonic anhydrase. Proc Natl Acad Sci USA 1992;89:7786-90.

37. Yamamoto F, Steinberg RH. Effects of intravenous acetazolamide on retinal $\mathrm{pH}$ in the cat. Exp Eye Res 1992;54:711-8

38. Tsacopoulus M, Levy S. Effect of respiratory metabolic acidosis on inner-retinal $\mathrm{pH}$. Exp Eye Res 1976;23:495-504.

39. Yonemura D, Kawasaki K. New approaches to ophthalmic electrodiagnosis by retinal oscillatory potentials, drug-induced responses from retinal pigment epithelium and cone potential. Doc Ophthalmol 1979;48:163-222.

40. Bayne WF, Tao FT, Rogers G, Chu LC, Theeuwes F. Time course and disposition of methazolamide in human plasma and red blood cells. J Pharmaceut Sci 1981;70:75-81. 